\title{
Experiência de gestantes na consulta de Enfermagem com a construção do plano de parto
}

\author{
Pregnant women's experiences on the nurse consultation for the construction of a delivery plan \\ Experiencia de gestantes en la consulta de Enfermería con la construcción del plan de parto \\ Tatiane Herreira Trigueiro ${ }^{1}$ (D)

\section{RESUMO} Karine Amanda de Arruda ${ }^{2}$ (c) Sinderlândia Domingas dos Santos ${ }^{3}$ (1) Marilene Loewen Wall ${ }^{1}$ (D) Silvana Regina Rossi Kissula Souza ${ }^{1}$ (1) Letícia Siniski de Lima ${ }^{4}$ (B)

\begin{abstract}
1. Universidade Federal do Paraná, Departamento de Enfermagem. Curitiba, PR,
\end{abstract} Brasil.

2. Universidade Federal do Paraná, Curso de Graduação em Enfermagem. Curitiba, PR, Brasil.

3. Universidade Federal do Paraná, Programa de Pós-graduação Prática do Cuidado em Saúde. Curitiba, PR, Brasil.

4. Universidade Federal do Paraná, Programa de Pós-graduação em Enfermagem. Curitiba, PR, Brasil.
Autor correspondente:

Tatiane Herreira Trigueiro.

E-mail: tatiherreira@gmail.com

Recebido em 03/03/2021.

Aprovado em 26/09/2021.
Objetivo: Descrever a experiência das gestantes atendidas na Consulta de Enfermagem a partir de 37 semanas e que elaboraram seu plano de parto. Método: Pesquisa exploratória qualitativa, com 19 gestantes a partir de 37 semanas vinculadas à maternidade de risco habitual em Curitiba, Paraná, e que passaram pela consulta de enfermagem entre novembro de 2019 e março de 2020. Os dados foram coletados mediante entrevista e submetidos a análise de conteúdo temática. Resultados: As gestantes apresentaram desconhecimento sobre assuntos relacionados ao parto, o que contribui para o surgimento de dúvidas, medos e inseguranças. Também não conheciam, ou conheciam de forma superficial, o plano de parto. A consulta de enfermagem e o plano de parto na maternidade contribuíram para o esclarecimento de dúvidas, redução da ansiedade, possibilidade de fortalecimento e empoderamento da gestante e do acompanhante diante da oferta de informações para o parto vaginal e o estabelecimento de vínculo com a maternidade. Conclusões e implicações para a prática: Adequados à realidade e focados na individualidade da gestante, a consulta de enfermagem e o plano de parto foram respectivamente evidenciados como espaço para educação em saúde e ferramenta educativa, mostrando-se eficientes para a atuação do enfermeiro e melhora da assistência pré-natal.

Palavras-chave: Enfermagem Obstétrica. Enfermagem no consultório. Gestantes. Parto Humanizado. Educação Pré-Natal.

\section{ABSTRACT}

Objective: To describe the experience of pregnant women at 37 weeks of gestation or more attended at the Nursing Consultation who had developed their delivery plan. Method: Qualitative exploratory research with 19 pregnant women at 37 weeks of gestation or more with a bond to a low-risk maternity hospital in Curitiba, Paraná state, Brazil, who attended nursing consultation between November 2019 and March 2020. The data was collected through interviews and submitted to thematic content analysis. Results: The pregnant women were unaware of issues related to childbirth, which contributes to the emergence of doubts, fears, and insecurities. They also had no knowledge, or had only superficial knowledge, of the delivery plan. The nursing consultation and the maternity's delivery plan contributed to the clarification of doubts, the reduction of anxiety, the possibility of strengthening and empowering the pregnant woman and her companion in the face of the provision of information for vaginal delivery, and the establishment of a bond with the maternity. Conclusions and implications for the practice: Adequate to reality and focused on the individuality of the pregnant woman, the nursing consultation and the birth plan were shown to be a space for health education and an educational tool, respectively, efficient for the nurse's performance and improvement of prenatal care.

Keywords: Obstetric Nursing. Office Nursing. Pregnant Women. Humanizing Delivery. Prenatal Education.

\section{RESUMEN}

Objetivo: Describir la experiencia de gestantes atendidas en la Consulta de Enfermería a partir de las 37 semanas y que desarrollaron su plan de parto. Método: Investigación exploratoria cualitativa con 19 gestantes a partir de 37 semanas vinculadas al hospital de maternidad de riesgo habitual en Curitiba, Paraná, y que asistieron a la consulta de enfermería entre noviembre de 2019 y marzo de 2020. Los datos fueron recolectados a través de entrevistas y sometidos a análisis de contenido temático. Resultados: Las gestantes presentaron desconocimiento sobre temas relacionados con el parto, lo que contribuye al surgimiento de dudas, miedos e inseguridades. Tampoco conocían, o conocían superficialmente, el plan de parto. La consulta de enfermería y el plan de parto en la maternidad contribuyeron a la aclaración de dudas, la reducción de la ansiedad, la posibilidad de fortalecer y empoderar a la gestante y su acompañante ante la provisión de información para el parto vaginal y el establecimiento de un vínculo con la maternidad. Conclusiones e implicaciones para la práctica: Adecuada a la realidad y enfocada a la individualidad de la gestante, la consulta de enfermería y el plan de parto se evidenciaron como un espacio de educación en salud y una herramienta educativa, respectivamente, eficiente para el desempeño del enfermero y mejoramiento del cuidado prenatal.

Palabras clave: Enfermería Obstétrica. Enfermería de Consulta. Mujeres Embarazadas. Parto Humanizado. Educación Prenatal. 


\section{INTRODUÇÃO}

A assistência pré-natal consiste em um conjunto de ações clínicas, psicossociais e educativas que buscam prevenir e detectar precocemente patologias e complicações maternas e fetais, além de acompanhar o desenvolvimento da gestação com o objetivo de obter desfechos positivos para o bebê e a redução dos riscos maternos ${ }^{1,2}$. Tal assistência deve ser desenvolvida de forma a atender às demandas e necessidades específicas das gestantes, com a inclusão de condutas humanizadas e acolhedoras e ausência de intervenções desnecessárias ${ }^{1}$.

Por meio da atuação baseada em conhecimentos técnicos e científicos, a enfermagem obstétrica apresenta papel importante no pré-natal por sua capacitação para se realizar assistência humanizada, integral, resolutiva e de qualidade à gestante durante todo esse período, além de desempenhar importante papel no processo de educação em saúde ${ }^{3,4}$. Sua atuação como membro da equipe de saúde na assistência à gestante no pré-natal tem respaldo legal; uma de suas atribuições é a consulta de enfermagem como atividade privativa ${ }^{5,6}$. Na consulta, mediante uma abordagem contextualizada e participativa ${ }^{1}$, são fornecidas informações e orientações para a gestante, além de estímulo à expressão de suas necessidades e desejos, voltadas ao empoderamento e protagonismo durante todo o processo gravídico-puerperal ${ }^{7,8}$. Uma das ferramentas que pode contemplar essas questões durante a assistência de enfermagem no consultório para a educação pré-natal é o plano de parto.

Desde 1996 o plano de parto é uma das recomendações da Organização Mundial da Saúde para assistência ao parto normal $^{9}$, reforçado em 2018 em sua última atualização sobre a atenção ao parto e nascimento, na qual se reafirma que ele deve ser individualizado, considerando as preferências e necessidades das gestantes ${ }^{10}$. Trata-se de um documento escrito durante o período pré-natal, no qual a mulher grávida, após receber informações sobre a gravidez e parto e considerando seus valores e desejos pessoais, elabora preferências e toma decisões informadas acerca da prática de condutas obstétricas a serem adotadas ou não no momento do parto sob condições normais ${ }^{11}$. Assim, contribui para o empoderamento e incentivo à autonomia das mulheres a fim de torná-las protagonistas do seu processo parturitivo, exercendo o poder de decisão informada ${ }^{8}$.

O plano de parto é uma ferramenta de educação pré-natal e comunicação, pois proporciona o entendimento das gestantes a respeito dos fatores que envolvem o processo de parturição e facilita a troca de informações com a equipe multiprofissional que presta assistência durante esse processo ${ }^{12}$, uma vez que é por meio dele que a equipe conhecerá os desejos e preferências das gestantes, contribuindo para que estes sejam alcançados e respeitados.

A utilização do plano de parto demonstrou relação positiva com as condutas baseadas em evidências no processo de parturição em um hospital da Espanha, como aumento do contato pele a pele, do clampeamento tardio do cordão e da taxa de partos vaginais, ${ }^{11}$ resultado semelhante ao de outro estudo espanhol, que evidenciou relação direta entre maior grau de cumprimento do plano de parto com a obtenção de melhores resultados tanto para a mãe quanto para seu filho ${ }^{13}$.

Entretanto, sabe-se que é geralmente no final da gestação que as mulheres e seus acompanhantes apresentam-se mais ansiosos e estão mais receptivos e interessados no parto e as questões nele envolvidas ${ }^{7,14}$ e que, apesar da importância de a educação em saúde sobre o processo de parturição ocorrer em todos os momentos oportunos no pré-natal, há necessidade de se enfatizar, educar e relembrar determinados aspectos sobre esse momento e estabelecer vínculo com a maternidade de referência a partir do terceiro trimestre de gestação, preferencialmente a partir de 37 semanas.

Nesse sentido, compreendendo todos os fatores envolvidos na assistência pré-natal e as atribuições do enfermeiro nesse processo, a Consulta de Enfermagem a partir de 37 semanas, realizada em uma maternidade de risco habitual no município de Curitiba, Paraná, tem como um dos objetivos, além dos aspectos estabelecidos para uma consulta de pré-natal, elaborar o plano de parto em conjunto com a gestante e seu acompanhante, favorecer a formação de vínculo com a maternidade e orientar e esclarecer dúvidas sobre o trabalho de parto, o parto e o puerpério, de acordo com os aspectos legais e com as rotinas da maternidade.

Revisão Sistemática sobre os efeitos do uso do plano de parto no processo de nascimento, realizada em 2018, enfatizou a necessidade da realização de pesquisas sobre a temática, visto que, apesar de a análise das três publicações encontradas apontar para uma melhor experiência de parto nos grupos que utilizaram o plano de parto, ainda não há evidências fortes para realizar tal afirmação ${ }^{15}$. Assim, diante da necessidade de promover e disseminar o conhecimento dessa temática, emergiu a seguinte inquietação: Qual é a experiência das gestantes que participaram da Consulta de Enfermagem a partir de 37 semanas e elaboraram seu plano de parto? O objetivo deste artigo foi descrever a experiência das gestantes atendidas na Consulta de Enfermagem a partir de 37 semanas e que elaboraram seu plano de parto.

\section{MÉTODO}

Trata-se de pesquisa exploratória de abordagem qualitativa, vinculada a um projeto de extensão do curso de graduação em enfermagem de uma universidade pública no município de Curitiba, Paraná, e desenvolvida em uma maternidade pública de risco habitual desse município.

A maternidade pública de risco habitual em Curitiba trabalha com o modelo de atendimento humanizado e centrado nas gestantes, parturientes e puérperas. É dividida em Pronto Atendimento (PA), com média de 615 atendimentos/mês, o Centro Obstétrico, que possui seis leitos de pré-parto-puerpério (PPP) e três de observação clínica, com média de 200 partos/mês, o Alojamento Conjunto (AC), com 37 leitos, e a maternidade, que tem ainda 10 leitos de Unidade de Cuidados Intermediários para o Recém-Nascido. Possui também ambulatório para atendimento de ginecologia e obstetrícia com quatro consultórios, com capacidade média de 
produção de 2.112 consultas/mês para atendimento Médico, de Enfermagem, Psicologia, Fonoaudiologia e Assistência Social. Assim, essa maternidade atende a população de 38 Unidades Básicas de Saúde de Curitiba.

O projeto de extensão é realizado desde setembro de 2018 , por meio da oferta de consultas de enfermagem a partir de 37 semanas e elaboração de plano de parto de forma individualizada com as gestantes vinculadas à maternidade, as quais são apresentadas ao projeto por meio da visita à maternidade $e$ por cartazes colados no PA e, mediante interesse, realizam agendamento conforme disponibilidade de horário.

As consultas são desenvolvidas nas dependências do ambulatório da maternidade, ocorrem uma vez por semana no período vespertino, às sextas-feiras, e têm duração de aproximadamente uma hora. São atendidas em média cinco gestantes por semana e todas podem levar o acompanhante de sua escolha. As consultas têm como objetivo a formação de vínculo entre a maternidade e a gestante, o oferecimento de orientações sobre o parto e puerpério de acordo com os aspectos legais e com as rotinas da maternidade, o esclarecimento de dúvidas e a construção do plano de parto. Além disso, é realizado exame clínico, com aferição de sinais vitais, e exame físico obstétrico direcionado. Ao final, é realizada a evolução de enfermagem no sistema próprio da maternidade.

Essas consultas são conduzidas pelas discentes integrantes do projeto, graduandas do curso de enfermagem da universidade, sob orientação das docentes enfermeiras obstetras coordenadoras do projeto e com apoio das enfermeiras do setor. Após o término de cada consulta, as discentes e docentes informaram as gestantes e acompanhantes sobre a realização da pesquisa. Mediante interesse, as pesquisadoras, que estavam na sala reservada ao lado, eram avisadas e, então, as gestantes eram encaminhadas individualmente. A participação na pesquisa foi efetivada a partir da assinatura do Termo de Consentimento Livre e Esclarecido em duas vias e garantiu-se anonimato por meio da substituição dos nomes das participantes pela letra $G$ (gestante), seguida de algarismos arábicos de acordo com a ordem de realização das entrevistas (G1, G2 e assim por diante).

Os critérios de elegibilidade foram: gestantes maiores de 18 anos, vinculadas à maternidade e que participaram da Consulta de Enfermagem a partir de 37 semanas e da elaboração do plano de parto. Para a coleta dos dados, foram realizadas entrevistas pela docente responsável pela pesquisa acompanhada por uma discente, no período de novembro de 2019 a março de 2020, em cinco períodos vespertinos das sextas-feiras; das 20 gestantes convidadas a participar, 19 aceitaram e uma não aceitou por motivo de falta de tempo dela e do seu acompanhante para permanecer após a consulta. A coleta dos dados encerrou-se quando as pesquisadoras identificaram repetições nas falas e alcance do objetivo proposto, o que foi percebido na entrevista 17; realizaram-se mais duas entrevistas para constatação ${ }^{16}$.

Foi desenvolvido um roteiro de entrevista semiestruturada com a questão norteadora da entrevista: "Como foi para você a experiência de passar por essa Consulta de Enfermagem e elaborar o plano de parto?" Além disso, foram considerados os dados da evolução preenchida durante a consulta para caracterizar as participantes. As entrevistas resultaram em um documento de áudio com um total de uma hora, 50 minutos e 21 segundos de gravação.

Esta pesquisa foi apreciada e aprovada pelo comitê de ética da referida instituição sob o parecer 3.527.412, aprovado em 24 de março de 2019. Os aspectos éticos foram garantidos conforme a Resolução № 466 de 12 de dezembro de 2012, do Conselho Nacional de Saúde ${ }^{17}$.

Após a coleta, as entrevistas foram transcritas na íntegra, resultando em um documento com 34 páginas. Os dados foram analisados com base na análise de conteúdo temática, organizada em três fases: a pré-análise, a exploração do material e o tratamento dos resultados, inferência e interpretação. A primeira fase consiste no primeiro contato com os dados, na formulação das hipóteses e dos objetivos e no estabelecimento dos indicadores para interpretar os dados, seguindo as regras da exaustividade, representatividade, homogeneidade, pertinência e exclusividade. Na segunda fase, são identificadas as unidades de contexto, considerando o nível semântico do conteúdo. Em seguida, essas unidades são nomeadas formando as unidades de registro ou temas. Na terceira fase ocorre o tratamento, inferência e interpretação dos resultados, na qual, com base no referencial teórico, busca-se dar sentido à interpretação para que seja válida e significativa ${ }^{18}$.

Após leitura, releitura e análise das transcrições, foram identificadas 12 unidades de registro, ou temas, das quais, por afinidade e exclusão, emergiram três categorias denominadas: "Dificuldades e deficiências percebidas em relação ao pré-natal"; "A importância da divulgação e promoção de informações voltadas ao empoderamento de gestantes" e "Consulta de enfermagem como meio para educação em saúde e fortalecimento de vínculo com a gestante".

\section{RESULTADOS}

A faixa etária das participantes variou de 21 a 36 anos; 16 eram brancas e três pardas; 11 eram casadas, seis eram solteiras e duas estavam em união estável; 13 tinham o ensino superior, cinco tinham o segundo grau completo e uma tinha o ensino superior incompleto. Com relação ao histórico gestacional, 17 eram primigestas, uma secundigesta com uma cesárea anterior e uma multigesta com histórico de dois abortos anteriores; 14 realizaram acompanhamento pré-natal exclusivamente nas unidades de saúde às quais eram vinculadas e cinco gestantes realizaram o acompanhamento tanto na unidade de saúde quanto no plano de saúde particular.

O número de consultas de pré-natal realizadas variou de 5 a 14 consultas; 15 gestantes realizaram sete ou mais consultas, duas realizaram seis consultas, uma realizou cinco consultas e uma não teve a informação anotada no instrumento preenchido na consulta. Ressalta-se que a gestante que realizou cinco consultas e a gestante que não teve o número de consultas anotado realizaram o acompanhamento pré-natal tanto pela 
unidade de saúde quanto pelo plano de saúde. Dessa forma, não foi possível ter acesso às anotações realizadas na carteirinha da gestante utilizada pelo plano de saúde, uma vez que não foram apresentadas no momento da consulta. Das 19 entrevistadas, 17 realizaram visita à maternidade em data anterior à entrevista. Das duas que não realizaram, uma tinha visita agendada em data posterior e outra conhecia a maternidade de internamentos anteriores.

\section{Dificuldades e deficiências percebidas em relação ao pré-natal}

Foi possível identificar nas falas das entrevistadas questões relacionadas às dificuldades e deficiências durante o pré-natal envolvendo o conteúdo abordado durante as consultas e a comunicação entre as unidades de saúde e a maternidade de referência. Assim, sete entrevistadas relataram que não receberam informações sobre o parto durante as consultas nas unidades de saúde:

Ela (profissional da unidade de saúde) sempre acompanhava mais os exames [...]. Agora falar, abordar sobre parto, como ia acontecer e tal foi só a consulta de hoje. (G1)

Não. Era consulta bem básica assim. (G19)

Apenas duas entrevistadas afirmaram que receberam informação sobre o momento do parto durante as consultas de pré-natal e outras quatro relataram que o tema foi comentado algumas vezes, principalmente quando questionado por elas:

Às vezes eu perguntava alguma coisa, daí ele explicava algumas dúvidas que eu tinha. (G6)

Tudo que a gente perguntou, ele (médico) sempre explicou certinho e tal, mas se a gente não perguntar é aquela coisa, né "Oi, tudo bem? Tchau". (G9)

Com relação à comunicação entre as unidades de saúde e a maternidade, três gestantes enfatizaram a necessidade de melhorias na comunicação entre esses serviços, pois a falta de informação por parte das unidades sobre o que a maternidade oferece para as gestantes necessita ser revista. Nesse sentido, o desconhecimento sobre as rotinas e a equipe da maternidade de referência apareceu na fala de três entrevistadas, indicando sentimento de insegurança:

Eu acho que é até uma falha do postinho, [...] imagina quantas mães não sabem, não têm essa informação. Eles deviam pegar e informar ó: "vai lá, se informa, tá aqui o telefone de lá, lá tem um plano legal, você pode conhecer o local [...]". O que é importante, assim, para mãe saber, principalmente quando é de primeira viagem [...], que tá perdida. (G3)

[...] vai saber se olugar que você vai ter o neném também vê as coisas assim. Então, eu sei que a Maternidade $\mathrm{X}$ e a Maternidade Y são referência em parto humanizado. Mas uma coisa é dizer que é referência, outra coisa é você ver que realmente os procedimentos condizem com aquilo que falam que é, né?! (G18)

E outras duas referiram a importância de conhecer previamente a equipe e quais são os profissionais necessários no momento do parto:

Eu acho que o que me assusta mais não é o parto em si, são os profissionais que podem me atender, entendeu? Às vezes, você pode ter muita sorte, mas como você pode não ter sorte [...]. (G7)

Acho que seria legal a gente conhecer as enfermeiras que vão atender a gente antes. [...] a gente saber quem vai ficar com a gente lá dentro. Qual que vai ser a médica ou a enfermeira. [... ] ver pelo menos a pessoa antes [...]. Eu acho que acalmaria mais a gente saber [...]. (G2)

Essa categoria possibilitou a identificação dos pontos positivos, fragilidades e necessidades apontadas pelo grupo de entrevistadas, assim como a necessidade de integração entre atenção primária e maternidade.

\section{A importância da divulgação e promoção de informações voltadas ao empoderamento de gestantes}

Com relação ao plano de parto, 13 entrevistadas relataram que desconheciam esse instrumento ou ouviram falar, mas não sabiam exatamente o que era:

Assim, não sabia o conteúdo todo, mas um pouco eu
imaginava o que era. (G4) Não, não tinha ideia. Nem imaginava que tinha né. Achei super importante. (G6)

Eu tinha lido em algum lugar, assim, mas eu só achava que tinha na rede particular. Não achava que tinha na rede pública. (G16)

Foi identificado na fala de 15 entrevistadas que diferentes meios proporcionam acesso à informação para o conhecimento do plano de parto e de questões relacionadas à gestação e ao parto, como: a visita à maternidade, as redes de apoio e os recursos presentes na internet, como sites de busca, redes sociais e documentários:

Eu fiquei sabendo do plano de parto na visita. Aí eu já me interessei. Falei: "Ah, que legal! Vou ver como que é. Se eu posso fazer". (G2)

Algumas amigas que já têm filhos, assim, que fizeram os planos de parto e a gente pode acompanhar [...]. E também de documentários, coisas que a gente assistiu. (G9) 
Obviamente, porque a gente, mãe de primeira viagem, acaba buscando muita informação na internet, né?! $A$ gente vai atrás de quem já passou por isso. (G11)

[...] eu estou num grupo de mães (em rede social na internet), daí elas sempre comentam né. A gente troca experiência. (G12)

Três entrevistadas referiram também que a possibilidade de conhecer a maternidade e assistir a palestra ofertada no local proporcionaram um sentimento de alívio ao identificarem que as práticas adotadas iam ao encontro de seus princípios e desejos:

E aí a gente veio na visita da maternidade e eu saí muito feliz. Eu até chorei, porque todas as coisas que me faziam querer ter um parto domiciliar, eu escutei que aqui eram normas. Então eu fiquei muito grata, eu falei: "Meu Deus! Eu fiquei preocupada à toa, fiquei triste à toa, né?!" $E$ aqui eu vou ter tudo que eu sempre quis e gratuito. Eu saí muito grata e até muito emocionada. (G9)

[...] quando a gente veio aqui visitar, foi bem esclarecedor. [...] então me passou uma impressão muito boa de como são os procedimentos. A gente ouve de violência obstétrica [...]. Aqui (maternidade) parece bem tranquilo. (G13)

Então mostrou assim, realmente é humanizado né?! Então te deixa mais tranquila também em relação a isso, né?! (G18)

Essa categoria evidencia o desconhecimento sobre o plano de parto nesse grupo de gestantes, no qual houve a necessidade de buscar informações em diferentes meios de comunicação sobre o parto; a possibilidade de se aproximar da maternidade trouxe sentimentos positivos.

\section{Consulta de enfermagem como meio para educação em saúde e fortalecimento de vínculo com a gestante}

Nas falas de 12 gestantes, foi possível observar que as expectativas em relação ao parto estavam relacionadas a diversos fatores, como preocupação com a saúde do bebê, momento de ir para a maternidade, desejo pelo parto vaginal, medo da dor e humanização do atendimento:

Que ocorra tudo bem. Que eu não precise ir agora para sala de cirurgia, né?! Para passar por uma cesárea. (G15)

A minha expectativa é que seja realmente humanizado, que não façam nenhum tipo de procedimento, assim, sem me falar né? Porque eu sei que tem alguns procedimentos que são essenciais ali pro bem estar, tanto meu quanto dela na hora, mas eu gostaria muito de ser informada. Ser tratada com respeito, tanto eu quanto ela. (G17)

Evidenciou-se nas falas de 14 entrevistadas que as dúvidas apresentadas estavam relacionadas, principalmente, ao trabalho de parto, aos processos fisiológicos do parto, amamentação, direitos das gestantes e funcionamento e rotinas da maternidade:

Então, para saber [...] se tem direito de ter o acompanhante, né?! 24 horas mesmo. Eu tinha bastante dúvida em questão disso. (G1)

[...] dúvida do momento do parto mesmo, como vai ser. Não é nem que não foi explicado, mas por essa coisa mesmo de ser a primeira vez. Tipo: "Nossa, quanto tempo depois que sai a placenta?" Né?! Pô, por que nunca ninguém falou isso que não sai junto com o bebê? (G9)

A dúvida que eu mais tinha era em relação à amamentação, que era minha dúvida principal. (G10)

Nesse sentido, na fala de 16 entrevistadas, a consulta de enfermagem foi evidenciada como um importante meio para o esclarecimento das dúvidas, por meio da promoção do conhecimento envolvendo os assuntos abordados. Quatro destas apontaram esse momento como importante para o esclarecimento das dúvidas dos acompanhantes:

Ah, eu gostei! Achei bem legal. Acho que é bem importante para mãe, porque tira um pouco das dúvidas que a gente tem. (G2)

O bom é que esclarece como que realmente vai ser né. Então não fica mais naquele escuro de sei lá, vou chegar e vamos ver o que vai ser [...]. Então eu sei já o caminhar, como é que vão acontecer as coisas. (G3)

Que ele (acompanhante) não pode vir no dia da palestra. Então, daí eu falei: "No dia do plano de parto eu quero que você vá, né?! Para você ouvir tudo e ter todas as informações." É importante também para ele não ficar perdido. (G1)

Das entrevistadas, 13 afirmaram que passar pela consulta proporcionou redução da ansiedade e medo e que se sentiram mais tranquilas, seguras e confiantes para o parto na maternidade, tanto em relação aos aspectos fisiológicos quanto às rotinas e condutas desenvolvidas:

Passou segurança para mim [...]. Eu fiquei mais tranquila em saber que, por exemplo, eu posso, na hora do meu parto, escolher a posição para eu poder ter o meu bebê e me tranquiliza saber isso [...]. (G2)

Porque eu estava muito ansiosa e muito receosa também, de como que vai ser essa questão de dor. Então elas (discentes de enfermagem) passaram essa tranquilidade. Eu gostei muito! Eu acredito que agora eu estou mais tranquila, mais confiante também. (G6)

[...] entender como funciona aqui dentro, quais são os princípios, o que preza, deixa a gente bem tranquila. Eu acho que ela reforça que eu vou ter o que eu sempre 
quis. Me deixa mais tranquila ainda para o momento do parto. (G9)

Além disso, foi evidenciado que a consulta de enfermagem proporcionou um atendimento individualizado, conforme três entrevistadas, e um ambiente acolhedor, de acordo com duas entrevistadas:

Eu acho que aqui você tem mais possibilidade de tirar sua dúvida, né?! [...] por ser um contato mais individual. (G7)

Vir para consulta foi bem o que eu imaginava: acolhimento. As meninas são muito simpáticas, né?! Deixa mais próximo, chama o neném pelo nome. São detalhes pequenininhos, parece bobo, mas é minha primeira gestação, né?! Por mais que vocês podem receber várias grávidas, cada uma está com um bebê na barriga. Então vê o carinho com que elas trataram. (G18)

Assim, aponta-se a necessidade da aproximação da gestante no final do pré-natal com a maternidade de referência para esclarecimentos de dúvidas e informações referentes ao processo de parturição baseado em evidências e sobre amamentação, que se estendeu também ao acompanhante. Essa formação de vínculo com a maternidade ao final da gestação foi promovida com a consulta de enfermagem e a construção do plano de parto.

\section{DISCUSSÃO}

A caracterização das participantes deste estudo no que se refere à idade, situação conjugal e histórico gestacional é semelhante aos dados apresentados por pesquisa em âmbito nacional, demonstrando maior número de gestantes jovens e adultas jovens, com companheiro e primigestas. Com relação ao grau de escolarização, houve predomínio de gestantes com ensino superior, resultado contrário aos dados apresentados nesta pesquisa, em que a escolaridade materna predominante foi o ensino médio completo. ${ }^{19}$

Todas as gestantes entrevistadas estavam vinculadas à maternidade de estudo e a reconheciam como local de referência para o parto, visto que a vinculação era um dos requisitos para participação da consulta de enfermagem; tal fato vai de encontro a outros estudos, que apontam número elevado de gestantes que não receberam informações sobre sua vinculação a uma maternidade de referência, contribuindo para a peregrinação ${ }^{19,20,21}$.

Apesar de a maioria das gestantes ter realizado visita à maternidade, foi identificado na fala de algumas delas que o conhecimento a respeito dessa possibilidade não foi obtido através da equipe da unidade de saúde em que realizavam o pré-natal, mas sim por outros meios. Isso aponta que, nessa realidade, existem falhas de comunicação entre o local de prénatal e a maternidade a respeito do que esta oferece. Tais achados são semelhantes aos resultados de pesquisa realizada em Florianópolis, Santa Catarina, com 12 gestantes acompanhadas na atenção primária do município, a qual aponta que as falhas nas orientações recebidas por elas a respeito da maternidade de referência são problemas relacionados à falta de integração do trabalho em rede ${ }^{22}$.

Dessa forma, verifica-se a importância da articulação entre atenção primária e maternidade para o planejamento de ações para orientação das gestantes, visto que conhecer a maternidade de referência previamente permite familiarizar-se com as instalações, conhecer as rotinas e ainda compreender como o parto é abordado nessa realidade ${ }^{23}$. Isso pode contribuir para a redução da ansiedade relacionada ao parto ${ }^{24}$, conforme relatado por algumas gestantes desta pesquisa.

Quase a totalidade das gestantes entrevistadas realizou o quantitativo mínimo de consultas pré-natal recomendado pelo Ministério da Saúde, que deve ser igual ou superior a seis consultas ${ }^{1}$. Embora a assistência pré-natal tenha se mostrado adequada quantitativamente, os resultados desta pesquisa apontam deficiências relacionadas ao conteúdo abordado sobre o parto durante as consultas e a educação pré-natal. Tais achados corroboram diferentes estudos. Estudo realizado em Brasília, com mulheres primigestas, apontou que o tema parto não esteve presente nas consultas de pré-natal da maior parte das gestantes, mesmo algumas já estando próximas à data provável do parto ${ }^{25}$. Outro estudo, desenvolvido em uma maternidade pública de risco habitual, em Londrina, Paraná, apontou que $52 \%$ das 358 participantes da pesquisa não receberam qualquer orientação para o parto durante as consultas de pré-natal; destas, 38,2\% eram primigestas. Associando-se o número de consultas, $81,7 \%$ das gestantes que realizaram seis consultas ou mais não receberam informações sobre o parto ${ }^{21}$, evidenciando a necessidade de incorporar a temática parto nas consultas de pré-natal. A literatura destaca que a questão qualitativa do pré-natal deixa a desejar ao mostrar a necessidade de abordar, entre outras temáticas, os temas relacionados ao trabalho de parto e parto durante a assistência pré-natal ${ }^{22}$.

Um dos instrumentos que pode auxiliar na educação prénatal sobre o parto durante a gestação é o plano de parto. O desconhecimento ou conhecimento superficial por parte das participantes foram evidenciados, e isso não é realidade apenas nesta pesquisa. Outros estudos apontam que grande parte das gestantes desconhece esse instrumento ${ }^{14,26}$. O desconhecimento por parte dos profissionais e as barreiras impostas pelos serviços de saúde também merecem destaque. Estudo realizado com 15 enfermeiros atuantes na atenção primária, em um município do Rio Grande do Sul, apontou o desconhecimento e a compreensão errônea do plano de parto por parte de todos os profissionais entrevistados. Contudo, esses profissionais demonstraram interesse em utilizar essa ferramenta, mas destacaram a necessidade de capacitação para sua utilização, de parceria com as maternidades e da mudança no modelo de atenção, para que as questões planejadas na atenção primária sejam executadas na atenção hospitalar, visto que nessa realidade a atenção ao parto está embasada no modelo biomédico ${ }^{7}$.

Ressalta-se que, na maternidade de pesquisa, o foco é a humanização e o respeito no atendimento às gestantes. $O$ plano 
de parto foi construído em parceria entre academia e profissionais da maternidade, mostrando-se condizente com a realidade de atendimento e fazendo com que, assim, fosse aceito e seguido pelos membros da equipe.

Pesquisa em uma maternidade da Escócia com mulheres (antes e após o parto) e funcionários locais sobre o uso do plano de parto apontou alguns benefícios, como a oportunidade de as mulheres apontarem suas preferências, a possibilidade de estimular discussões com a equipe e como um meio de lidar com a ansiedade. Contudo, nem todas as mulheres fizeram seu plano de parto ou compreenderam o seu propósito, pois não sabiam da oportunidade de fazê-lo; outras não conseguiram ter o acesso e outras ficaram relutantes em fazê-lo. A equipe reconheceu a necessidade de apoiar as mulheres com o plano de parto, mas observou desafios práticos para isso, como a necessidade de treinamento e tempo no encontro com as mulheres para a elaboração do documento ${ }^{27}$.

O desconhecimento por grande parte das gestantes, dos profissionais e serviços de saúde a respeito do plano de parto e a falta de incentivo e apoio profissional para sua construção são fatores que interferem na não utilização desse instrumento ${ }^{26,28}$ contribuindo para a ideia errônea de que ele é restrito a alguns locais ${ }^{26}$ ou como uso exclusivo do sistema privado de saúde, como apontado por uma das entrevistadas desta pesquisa. Isso reforça a importância do profissional de saúde na divulgação e incentivo ao uso do plano de parto, conforme estudo realizado em unidades de saúde de Belo Horizonte, Minas Gerais, que apontou os profissionais de saúde como os principais divulgadores do plano de parto durante as consultas de pré-natal, para as gestantes participantes da pesquisa ${ }^{14}$

Pesquisa realizada na Espanha sobre a influência do plano de parto aponta para a necessidade da criação de políticas públicas para divulgação e formas de promoção desse documento, de modo a incentivar o uso e seu conhecimento entre as gestantes. Tal pesquisa reconhece ainda que a enfermeira obstétrica na Atenção Primária é a profissional adequada para acompanhar a mulher na elaboração desse documento ${ }^{11}$.

Cabe destacar que a visita à maternidade foi o principal meio de divulgação da Consulta de Enfermagem a partir de 37 semanas. Dentre os tópicos abordados pela enfermeira responsável pela visita, estava a possibilidade de participar dessa consulta para a construção do plano de parto. Esse foi o momento em que algumas das gestantes ouviram falar pela primeira vez desse instrumento. Cabe ressaltar que a construção do plano de parto não era rotina na maternidade, sendo implantada após parceria entre a maternidade e o curso de graduação em enfermagem da universidade por meio de um projeto de extensão universitária

Outras fontes apontadas pelas gestantes como meio para conhecimento do plano de parto e outras questões relacionadas à gestação e parto foram as redes de apoio e a internet. Evidências apontam que a internet é a principal fonte para busca de informações em saúde, que a aquisição dessas informações permite maior autonomia e liberdade de escolha ${ }^{29}$ e que as experiências compartilhadas por terceiros contribuem para a tomada de decisão das mulheres ${ }^{30}$.

Durante a assistência e educação pré-natal, o enfermeiro tem papel importante para estimular e auxiliar a gestante a expressar suas necessidades e desejos e orientá-la na construção do seu plano de parto 7 . Quando realiza essas ações, o enfermeiro exerce seu papel de educador, promovendo o conhecimento da gestante e estimulando o exercício da sua autonomia para que esta assuma o protagonismo durante a gestação, parto e puerpério ${ }^{7,26}$. Para isso, é essencial que o enfermeiro conheça e compreenda o objetivo desse instrumento e veja sua utilização e construção como meios para qualificação da sua prática profissional e para melhora da assistência voltada às gestantes ${ }^{7,8}$.

A construção conjunta do plano de parto contribui para o desenvolvimento de confiança e segurança, além de promover o estabelecimento de vínculo da gestante com o profissional e com o serviço ${ }^{31}$. Ressalta-se a importância da orientação profissional na construção do plano de parto para que as gestantes compreendam também que o trabalho de parto e parto não são momentos totalmente previsíveis e que, frente a situações inesperadas, pode ser necessária a flexibilização das escolhas ${ }^{28}$, o que não exclui, porém, o fato de que a parturiente precisa ser comunicada na ocorrência de situações que necessitem de alterações ${ }^{8}$. A orientação também é necessária para que essa ferramenta seja aplicável à realidade em que o parto acontecerá Isso impede a criação de expectativas irrealistas e a insatisfação com a sua utilização ${ }^{28}$.

Há necessidade de os profissionais, com destaque para o enfermeiro, reforçarem as ações de educação em saúde para melhorar a assistência e favorecer o estabelecimento de vínculo entre as gestantes e o serviço de saúde ${ }^{32}$. Em consonância, destaca-se que o processo educativo deve atingir profissionais e gestantes e que sua ampliação é necessária para favorecer o empoderamento e escolha informada das gestantes em relação ao parto ${ }^{33}$.

É necessário que exista a compreensão do processo de parturição como único para cada mulher e a visão de que ela é participante ativa desse processo. Ela deve ser acolhida e provida de esclarecimentos, orientação e incentivo para compreender os fatores envolvidos no processo de parto e nascimento e suas possibilidades de escolha para então optar por aquelas voltadas às suas necessidades e preferências, tornando-se corresponsáveis nesse processo ${ }^{34}$.

\section{CONSIDERAÇÕES FINAIS}

O período final da gestação é marcado por dúvidas, medos e incertezas relacionados ao processo de parturição, principalmente quando é vivido pela primeira vez. Somado a isso, com base nos achados apresentados, outro fator que contribui para a presença desses sentimentos pode estar associado às dificuldades com orientações recebidas no pré-natal. Aponta-se a necessidade de melhorias das ações de educação em saúde, das orientações e da divulgação de informações nos encontros entre gestante e profissional de saúde. 
Considerando a consulta de enfermagem como inerente à prática profissional do enfermeiro, ressalta-se a importância da sua utilização como meio para garantir a totalidade da atenção voltada às gestantes. Destaca-se que a consulta de enfermagem de prénatal realizada dentro da maternidade possibilita perspectivas de fortalecimento do vínculo e perspectivas de melhoria do cenário obstétrico a partir da redução de sentimentos negativos da gestante e acompanhante e que pode resultar em processos de partos com experiência positiva. Não obstante, incentiva a inserção da Enfermagem no consultório das maternidades e a necessidade de atualização e inserção da enfermagem obstétrica nos serviços.

A satisfação com a consulta de enfermagem a partir de 37 semanas e com a elaboração do plano de parto está relacionada à possibilidade de proporcionar um ambiente acolhedor e individualizado, estabelecer vínculo e aproximação da maternidade, bem como esclarecer dúvidas e reduzir ansiedade e medo. A partir do momento em que a gestante se sente acolhida, apropria-se do conhecimento e compreende seus direitos, é capaz de se tornar ativa, questionar e realizar escolhas informadas para esse momento.

Referente ao plano de parto, percebe-se a necessidade de maior utilização e divulgação desse documento. As estratégias para incorporação do plano de parto nos serviços de saúde devem ser discutidas com a gestão local e o documento precisa ser desenvolvido a partir do envolvimento dos profissionais de saúde que atuam nas maternidades, para que possa ser adaptado e condizente com a realidade e discutido com as gestantes e acompanhantes. Não obstante, deve estar em constante atualização para que seja uma ferramenta de cuidado que possa oferecer melhores indicadores e experiências positivas de parto para todos envolvidos.

Destaca-se também a importância da aproximação entre universidade e o serviço para o desenvolvimento e fortalecimento de ações voltadas à melhoria da assistência prestada à população, visto que a incorporação dessa modalidade de atendimento foi fortalecida e instituída a partir dessa parceria. Assim, ressaltase a contribuição para a Enfermagem mediante sua inserção, conhecimento e protagonismo nas consultas pré-natais e na assistência direta ao parto, a partir do reconhecimento pelas gestantes e acompanhantes, assim como pela equipe multiprofissional.

Como limitação do estudo, tem-se o fato de a pesquisa ter sido realizada em apenas uma maternidade, com um grupo restrito de gestantes, impossibilitando a generalização dos resultados, visto que o projeto de extensão ocorre somente na maternidade local de estudo. Desse modo, aponta-se a necessidade de outros estudos dessa natureza em diversas localidades do país que também realizam essa modalidade de consulta de enfermagem e elaboração do plano de parto com vistas a compreender a experiência da participação das gestantes e acompanhantes em diferentes cenários.

\section{CONTRIBUIÇÕES DOS AUTORES}

Desenho do estudo. Marilene Loewen Wall. Letícia Siniski de Lima Tatiane Herreira Trigueiro.

Coleta ou produção dos dados. Karine Amanda de Arruda.
Análise de dados. Karine Amanda de Arruda. Tatiane Herreira Trigueiro.

Interpretação dos resultados. Karine Amanda de Arruda. Sinderlândia Domingas dos Santos. Marilene Loewen Wall. Tatiane Herreira Trigueiro. Tatiane Herreira Trigueiro.

Redação e revisão crítica do manuscrito. Tatiane Herreira Trigueiro. Karine Amanda de Arruda. Sinderlândia Domingas dos Santos. Marilene Loewen Wall. Silvana Regina Rossi Kissula Souza. Letícia Siniski de Lima.

Aprovação da versão final do artigo. Tatiane Herreira Trigueiro. Karine Amanda de Arruda. Sinderlândia Domingas dos Santos. Marilene Loewen Wall. Silvana Regina Rossi Kissula Souza. Letícia Siniski de Lima.

Responsabilidade por todos os aspectos do conteúdo e a integridade do artigo publicado. Tatiane Herreira Trigueiro. Karine Amanda de Arruda. Sinderlândia Domingas dos Santos. Marilene Loewen Wall. Silvana Regina Rossi Kissula Souza. Letícia Siniski de Lima.

\section{EDITOR CIENTÍFICO}

Ivone Evangelista Cabral (D)

\section{EDITOR ASSOCIADO}

\author{
Stela Maris de Melo Padoin (1)
}

\section{REFERÊNCIAS}

1. Ministério da Saúde (BR). Atenção ao pré-natal de baixo risco. $1^{\underline{a}}$ ed Brasília: Ministério da Saúde; 2013.

2. Peixoto S, Famá EAB, Facca TA, Mathias CV. Panorama da assistência pré-natal: conceito, importância e objetivos. In: Peixoto S., editor. Manual de assistência pré-natal. 2ª ed. São Paulo: Febrasgo; 2014. p. 13-19.

3. Rocha AC, Andrade GS. Atenção da equipe de enfermagem durante o pré-natal: percepção das gestantes atendidas na rede básica de Itapuranga-GO em diferentes contextos sociais. Revista Enfermagem Contemporânea. 2017;6(1):30-41. http://dx.doi.org/10.17267/23173378rec.v6i1.1153.

4. Leal NJ, Barreiro MSC, Mendes RB, Freitas CKAC. Prenatal care: nurses testimonial. Rev Fund Care Online. 2018;10(1):113-22.

5. Lei $n^{0} 7.498$, de 25 de junho de 1986 (BR). Dispõe sobre a regulamentação do exercício da enfermagem, e dá outras providências. Diário Oficial da União, Brasília (DF). 22 jun 1986 [citado 20 abr 2020]. Disponíve em: http://www.planalto.gov.br/ccivil_03/LEIS/L7498.htm.

6. Resolução $n^{\circ}$ 516, de 23 de junho de 2016 (BR). Normatiza a atuação e a responsabilidade do Enfermeiro, Enfermeiro Obstetra e Obstetriz na assistência às gestantes, parturientes, puérperas e recém-nascidos nos Serviços de Obstetrícia, Centros de Parto Normal e/ou Casas de Parto e outros locais onde ocorra essa assistência; estabelece critérios para registro de títulos de Enfermeiro Obstetra e Obstetriz no âmbito do Sistema Cofen/Conselhos Regionais de Enfermagem, e dá outras providências. Diário Oficial da União, Brasília (DF). 27 jun 2016: 121 Seção 1: 92.

7. Barros APZ, Lipinski JM, Sehnem GD, Rodrigues NA, Zambiazi ES. Conhecimento de enfermeiras sobre plano de parto. Rev Enferm UFSM. 2017;7(1):69-79. http://dx.doi.org/10.5902/2179769223270.

8. Silva ALNV, Neves AB, Sgarbi AKG, Souza RA. Plano de parto: ferramenta para o empoderamento de mulheres durante a assistência de enfermagem. Rev Enferm UFSM. 2017;7(1):144-51. http://dx.doi. org/10.5902/2179769222531. 
9. World Health Organization. Safe motherhood division of reproductive. Maternal and newborn health. Safe motherhood. Care in Normal Birth: a practical guide. Genebra: WHO; 1996.

10. World Health Organization. WHO recommendations: intrapartum care for a positive childbirth experience. Geneva: WHO; 2018.

11. Suárez-Cortés M, Armero-Barranco D, Canteras-Jordana M, MartínezRoche ME. Use and influence of Delivery and Birth Plans in the humanizing delivery process. Rev Lat Am Enfermagem. 2015;23(3):520-6. http:// dx.doi.org/10.1590/0104-1169.0067.2583. PMid:26155015.

12. Aragon M, Chhoa E, Dayan R, Kluftinger A, Lohn Z, Buhler K. Perspectives of expectant women and health care providers on birth plans. J Obstet Gynaecol Can.2013;35(11):979-85. http://dx.doi.org/10.1016/S17012163(15)30785-4. PMid:24246397.

13. Hidalgo-Lopezosa P, Hidalgo-Maestre M, Rodríguez-Borrego MA. Birth plan compliance and its relation to maternal and neonatal outcomes. Rev Lat Am Enfermagem. 2017;25(0):e2953. http://dx.doi.org/10.1590/15188345.2007.2953. PMid:29236838.

14. Silva SG, Silva EL, Souza KV, Oliveira DCC. Perfil de gestantes participantes de rodas de conversa sobre o plano de parto. Enfermagem Obstétrica. 2015;2(1):9-14.

15. Mirghafourvand M, Charandabi SMA, Ghanbari-Homayi S, Jahangiry L, Nahaee J, Hadian T. Effect of birth plans on childbirth experience: a systematic review. Int J Nurs Pract. 2019;25(4):e12722. http://dx.doi. org/10.1111/ijn.12722. PMid:30675962.

16. Fontanella BJM, Luchesi BM, Saidel MGB, Ricas J, Turato ER, Melo DG Amostragem em pesquisas qualitativas: proposta de procedimentos para constatar saturação teórica. Cad Saude Publica. 2011;27(2):388-94. http://dx.doi.org/10.1590/S0102-311X2011000200020. PMid:21359475.

17. Resolução $n^{\circ} 466$, de 12 de dezembro de 2012 (BR). Aprova normas regulamentadoras de pesquisas envolvendo seres humanos. Diário Oficial da União, Brasília (DF). 13 jul 2013: Seção 1: 59.

18. Bardin L. Análise de conteúdo. São Paulo: Edições 70; 2015.

19. Viellas EF, Domingues RMSM, Dias MAB, Gama SGN, Theme Filha MM, Costa JV et al. Assistência pré-natal no Brasil. Cad Saude Publica. 2014;30(supl 1):S85-100. http://dx.doi.org/10.1590/0102-311X00126013. PMid:25167194.

20. Domingues RMSM, Hartz ZMA, Dias MAB, Leal MC. Avaliação da adequação da assistência pré-natal na rede SUS do Município do Rio de Janeiro, Brasil. Cad Saude Publica. 2012;28(3):425-37. http:// dx.doi.org/10.1590/S0102-311X2012000300003. PMid:22415175.

21. Gonçalves MF, Teixeira EMB, Silva MAS, Corsi NM, Ferrari RAP, Pelloso $\mathrm{SM}$ et al. Pré-natal: preparo para o parto na atenção primária à saúde no sul do Brasil. Rev Gaucha Enferm. 2018;38(3): 0063. PMid:29538607.
22. Livramento DVP, Backes MTS, Damiani PR, Castillo LDR, Backes DS, Simão MAS. Percepções de gestantes acerca do cuidado pré-natal na atenção primária à saúde. Rev Gaúcha Enferm. 2019;40:e20180211. http://dx.doi.org/10.1590/1983-1447.2019.20180211.PMid:31188972.

23. Ministério da Saúde (BR). Humanização do parto e do nascimento. Universidade Estadual do Ceará. Cadernos HumanizaSUS. Brasília: Ministério da Saúde; 2014. 465 p.

24. Secretaria Municipal da Saúde de Curitiba. Pré-natal, parto, puerpério e atenção ao recém-nascido. Curitiba: Secretaria Municipal da Saúde; 2012. 250p.

25. Tostes NA, Seidl EMF. Expectativas de gestantes sobre o parto e suas percepções acerca da preparação para o parto. Temas Psicol. 2016;24(2):681-93. http://dx.doi.org/10.9788/TP2016.2-15.

26. Mouta RJO, Silva TMA, Melo PTS, Lopes NS, Moreira VA. Plano de parto como estratégia de empoderamento feminino. Rev Baiana Enferm 2017;31(4):e20275. http://dx.doi.org/10.18471/rbe.v31i4.20275.

27. Whitford HM, Entwistle VA, van Teijlingen E, Aitchison PE, Davidson T, Humphrey $T$ et al. Use of a birth plan within woman-held maternity records: a qualitative study with women and staff in northeast Scotland. Birth 2014;41(3):283-9. http://dx.doi.org/10.1111/birt.12109. PMid:24750377.

28. Medeiros RMK, Figueiredo G, Correa ACP, Barbieri M. Repercussões da utilização do plano de parto no processo de parturição. Rev Gaúcha Enferm. 2019;40:e20180233. http://dx.doi.org/10.1590/19831447.2019.20180233. PMid:31188973.

29. Moretti FA, Oliveira VE, Silva EMK. Acesso a informações de saúde na internet: uma questão de saúde pública? Rev Assoc Med Bras. 2012;58(6):650-8. http://dx.doi.org/10.1590/S0104-42302012000600008. PMid:23250092.

30. Lessa HF, Tyrrell MAR, Alves VH, Rodrigues DP. Informação para a opção pelo parto domiciliar planejado: um direito de escolha das mulheres. Texto Contexto Enferm. 2014;23(3):665-72. http://dx.doi. org/10.1590/0104-07072014000930013.

31. Loiola AMR, Alves VH, Vieira BDG, Rodrigues DP, Souza KV, Marchior GRS. Plano de parto como tecnologia do cuidado: experiência de puérperas em uma casa de parto. Cogitare Enferm. 2020;25.

32. Dias EG, Anjos GB, Alves L, Pereira SN, Campos LM. Ações do enfermeiro no pré-natal e a importância atribuída pelas gestantes. Revista SUSTINERE. 2018;6(1):52-62. http://dx.doi.org/10.12957/ sustinere.2018.31722.

33. Kottwitz F, Gouveia HG, Gonçalves AC. Via de parto preferida por puérperas e suas motivações. Esc Anna Nery. 2018;22(1):e20170013.

34. Pereira SB, Diaz CMG, Backes MTS, Ferreira CLL, Backes DS. Boas práticas de atenção ao parto e ao nascimento na perspectiva de profissionais de saúde. Rev Bras Enferm. 2018;71(supl 3):1313-9. http://dx.doi.org/10.1590/0034-7167-2016-0661. PMid:29972529. 